\title{
QUANDO POLÍTICAS DE RESISTÊNCIA SE TRANSFORMAM EM POLÍTICAS LINGUÍSTICAS OFICIAIS: O ESPANHOL NO NORDESTE BRASILEIRO
}

\author{
Cuando políticas de resistencia se convierten en políticas lingüísticas \\ oficiales: el español en el nordeste brasileño
}

\author{
José Veranildo Lopes da COSTA JUNIOR \\ Universidade do Estado do Rio Grande do Norte \\ jveranildo@hotmail.com \\ http://orcid.org/0000-002-2400-8715 \\ Tatiana Lourenço de CARVALHO \\ Universidade do Estado do Rio Grande do Norte \\ tatianacarvalho10@gmail.com \\ http://orcid.org/0000-0001-7014-0875
}

\begin{abstract}
RESUMO: As políticas linguísticas são entendidas, de modo geral, como um conjunto de decisões sobre o uso das línguas na esfera social, normalmente impostas pelo Estado através de documentos prescritivos oficiais. Contudo, quando analisamos a história do ensino de línguas no mundo ocidental, percebemos o surgimento de um conjunto de gestos de intervenção linguística (PONTE, 2010), que se contrapõe às macropolíticas instituídas pelas instituições governamentais que, muitas vezes, se fundamentam a partir de um paradigma da exclusão. Estes gestos de intervenção linguística também podem ser chamados de políticas de resistência, e são implementados por instituições periféricas, que não gozam do poder estatal como, por exemplo, as associações de professores e os movimentos estudantis. Com o objetivo de problematizar o processo pelo qual as políticas de resistência se transformam em políticas linguísticas oficiais, fundamentados em autores como Cooper (2000) e Ponte (2010), trataremos, neste artigo, do ensino de espanhol na região Nordeste de Brasil sob a perspectiva das micropolíticas que se opõem à revogação da Lei nacional $n^{\circ}$ 11.161/2005. As análises mostram que, no caso do espanhol, políticas de resistência vêm se transformando em políticas oficiais, garantindo o ensino desse idioma neolatino nos currículos de escolas estaduais e municipais.
\end{abstract}

PALAVRAS-CHAVE: Políticas linguísticas; Políticas de resistência; Espanhol no Nordeste. 
RESUMEN: Las políticas lingüísticas son entendidas, de modo general, como un conjunto de decisiones acerca del uso de las lenguas en la esfera social, a menudo impuestas por el Estado a partir de documentos prescriptivos oficiales. Sin embargo, cuando analizamos la historia de la enseñanza de lenguas en el mundo occidental, percibimos el surgimiento de gestos de intervención lingüística (PONTE, 2010), que se contraponen a las macropolíticas instituidas por las instituciones gubernamentales que, muchas veces, se fundamentan a partir de un paradigma de la exclusión. Estos gestos de intervención lingüística también pueden ser llamados de políticas de resistencia, y son implementados por instituciones periféricas, que no disfrutan del poder estatal como, por ejemplo, las asociaciones de profesorado y los movimientos estudiantiles. Con el objetivo de problematizar el proceso por el cual las políticas de resistencia se convierten en políticas lingüísticas oficiales, fundamentados en autores como Cooper (2000) y Ponte (2010), trataremos, en este artículo, sobre la enseñanza de español en la región Nordeste de Brasil bajo la perspectiva de las micropolíticas que se contraponen a la revocación de la Ley nacional no 11.161/2005. Los análisis muestran que, en el caso del español, políticas de resistencia vienen convirtiéndose en políticas oficiales, garantizando la enseñanza de este idioma neolatino en los currículos de escuelas estatales y municipales.

PALABRAS CLAVE: Políticas lingüísticas; Políticas de resistencia; Español en Nordeste.

\section{CONSIDERAÇÕES INICIAIS}

Entre movimentos políticos de inclusão e exclusão, a história do espanhol nas instituições brasileiras remonta a mais de 100 anos de existência. Em 2019, completamos um centenário do ensino da língua espanhola no Brasil, sendo o Colégio Pedro II, no Rio de Janeiro, considerado a primeira instituição educacional a oferecer aulas dessa língua neolatina,a partir do concurso público que, em 1919, aprovou o filólogo Antenor Nascentes para o cargo de docente de espanhol na referida escola (GUIMARÃES, 2011) ${ }^{1}$.

Nestes 100 anos da língua castelhana ${ }^{2}$ na educação nacional, podemos notar uma série de mudanças curriculares, de aprovação e revogação de leis sobre a presença de

\footnotetext{
${ }^{1}$ Há autores que mencionam que o espanhol esteve presente no Brasil desde 1870. Considerando um status de institucionalização da língua espanhola enquanto disciplina, optamos por fazer referência ao ano 1919 e ao contexto de ensino de castelhano no Colégio Pedro II, como momento que marca o centenário do ensino dessa língua no nosso país.

2 Para evitar repetições, utilizamos as palavras "espanhol" e "castelhano"como sinônimos sem estabelecer relações de poder entre os termos.
} 
diferentes línguas estrangeiras no currículo brasileiro, cuja discussão aparece, por exemplo, nas dissertações de Carvalho (2014) e Lemos (2008), no momento em que os autores abordam especificamente o ensino de espanhol. Nesse sentido, o complexo contexto acerca dos idiomas em nosso país mostra um traço importante quando se fala sobre línguas estrangeiras na escola: a presença ou a ausência dos idiomas no sistema educacional brasileiro (e nos documentos prescritivos) não é uma escolha exclusivamente pedagógica, mas também política.

Não se pode negar, por esta linha de raciocínio, que nós, alunos, professores e pesquisadores dos estudos hispânicos também entramos no "jogo" político, visando à defesa do ensino de espanhol no Brasil. Foi assim que, entre outras ações históricas de lutas e resistência, em 05 de agosto de 2005, sancionou-se a Lei ${ }^{\circ}$ 11.161/2005 que formalizava o ensino da língua espanhola no currículo nacional e, por consequência, iniciava um grande processo de difusão e democratização desse idioma neolatino em todo o país.

Naquela conjuntura, professores e demais interessados na difusão do castelhano no Brasil justificaram a importância da Lei $\mathrm{n}^{\circ} 11.161 / 2005$, principalmente, a partir do fortalecimento do MERCOSUL, criado desde 1991,argumentando que era necessário promover o ensino de língua portuguesa nos territórios hispânicos e, em contrapartida, difundir a língua espanhola em nosso país, como uma estratégia que promoveria laços entre nações latino-americanas, a partir do bloco econômico mencionado anteriormente.

Desde 2005,são inúmeras as pesquisas (artigos, trabalhos de conclusão de curso, dissertações e teses) que trazem o MERCOSUL como justificativa para a presença do castelhano no currículo nacional. Sedycias (2005), por exemplo, enumera dez razões sob as quais estudantes brasileiros devem aprender espanhol, sendo a quinta destas, o Mercado Comum do Sul.

Não estamos discordando de que, naquele momento, uma forte aliança econômica explicaria a importância de uma lei que oficializasse a presença do espanhol nas nossas escolas. Tampouco estamos criticando os colegas pesquisadores que defenderam (inclusive, nós, também o fizemos) o ensino deste idioma através do referido acordo intergovernamental.

Aqui, estamos refletindo sobre o fato de que o MERCOSUL era, antes de tudo, 
parte de uma estratégia política que visava à integração regional, por meio da economia, mas também da cultura. Contudo, enquanto "jogo" político, talvez tenhamos nos precipitado. Parece que nos aproveitamos de uma característica mercadológica para o ensino de espanhol e caímos em uma armadilha neoliberal, quando afirmamos que a importância da presença do castelhano nas escolas se justificava tendo em vista o bloco econômico latino-americano, que naquela ocasião, mostrava a sua indiscutível força.

Hoje, sabemos que o ensino de espanhol foi, de fato, muito impulsionado pelo MERCOSUL. No entanto, parece que ignoramos o fato de que, com a mudança de governos, acordos econômicos (e culturais) podem ser revogados e novos blocos financeiros, por exemplo, podem (re)surgir. Para ilustrar, podemos mencionar as ressonâncias do golpe político sofrido por Dilma Rousseff, quando Michel Temer iniciou as primeiras reformas educacionais que culminaram na revogação da Lei ${ }^{\circ}$ 11.161/2005 e que, também, resultaram em um primeiro movimento de desintegração continental.

Com a chegada de Temer à presidência e, posteriormente, com a eleição de Jair Bolsonaro, marcando a ascensão da ultradireita na política nacional, vimos uma retomada de um movimento de desintegração regional, em articulação com outros presidentes da América Latina, a exemplo de Sebastián Piñera, no Chile, e Maurício Macri, na Argentina. A partir disto, o MERCOSUL foi perdendo certo status político-econômico e nós fomos experimentando uma tentativa de invisibilidade do ensino de língua espanhola, tendo como contraponto uma imposição do ensino de língua inglesa no Brasil.

Considerando esta sucinta contextualização a respeito do centenário da presença do espanhol no Brasil, este artigo tem por objetivo traçar uma discussão sobre o processo pelo qual uma política linguística (doravante PL) de resistência se transforma em uma política linguística oficial, defendendo a ideia de que o ensino da língua espanhola no nosso país não se alicerça apenas em interesses econômicos, mas deve constituir-se em uma política educacional permanente e apartidária ${ }^{3}$, uma vez que este idioma neolatino faz parte da nossa identidade (ao lado de tantas outras línguas, como as de matriz indígena, por exemplo) e da nossa convivência com o outro que forma a nossa múltipla identidade

\footnotetext{
${ }^{3} \mathrm{O}$ ensino de língua espanhola não pode ser visto como uma política educacional partidária de esquerda. Do mesmo modo, os partidos de direita não podem tentar apagar o ensino do espanhol por concepções ideológicas. Trata-se de uma disciplina escolar que, independente de questões políticas, mostra-se de fundamental importância para a escola brasileira e para o aluno brasileiro, particularmente.
} 
cultural-linguística.

Nesta perspectiva, ao ressaltar o caráter político do espanhol no país, apresentaremos o surgimento de leis municipais e estaduais que oficializam o ensino da língua castelhana no Nordeste do Brasil, constituindo-se como uma micropolítica de resistência que se contrapõe à força de macropolíticas neoliberais, cuja filosofia hegemônica tem por finalidade promover uma desintegração regional.

Em relação à organização do texto,nosso artigo está dividido em três partes. No primeiro momento apresentamos uma revisão sobre o conceito de políticas linguísticas, buscando contribuir com a ideia de que atos de resistência podem se transformar em políticas linguísticas ditas oficiais. Em seguida, discutimos algumas PL acerca do ensino de espanhol, a partir da revogação da Lei $\mathrm{n}^{\mathrm{o}}$ 11.161/2005. Nesta parte, destacamos a criação e expansão do Movimento Fica Espanhol, a abertura e reativação de associações de professores e estudantes de espanhol, além da crescente luta nordestina pela aprovação de projetos de lei que mantenham ou instaurem a língua nas escolas da região. Por fim, na terceira parte do artigo, tratamos, de forma mais detalhada, da aprovação de novas leis municipais e estaduais que colocam o Nordeste como lócus de resistência a uma política neoliberal implantada por setores brasileiros de ultradireita, a exemplo do atual governo federal, que mantém uma política monolíngue e antidemocrática, além de uma nítida agenda de submissão aos interesses norte-americanos.

\section{POLÍTICAS LINGUÍSTICAS: REVISANDO O CONCEITO}

Na conjuntura brasileira, é a partir dos anos 90 que a Linguística Aplicada se viu como uma área transdisciplinar (SIGNORINI; CAVALCANTI, 1998) e indisciplinar (MOITA LOPES, 2006), dialogando com diversos campos do saber, como a Sociologia, a Filosofia, a Antropologia, a Psicologia, a Geografia, a Educação, entre outros. Nessa seara, os estudos sobre política aplicados às línguas ganharam relevo como crescimento de pesquisas no ramo das chamadas políticas linguísticas.

Sousa, Ponte e Sousa-Bernini (2019, p. 09) afirmam que "a política e planejamento linguístico (PPL), enquanto área disciplinar surge após a Segunda Guerra Mundial”. De acordo com as pesquisadoras, nos início dos anos 1960, alguns conceitos teóricos foram elaborados, como: “a primeira definição de planejamento linguístico realizada por 
Haugen, em 1959" (SOUSA; PONTE; SOUSA-BERNINI, 2019, p. 09), além da “distinção entre planejamento linguístico de corpus (planejamento relacionado à forma da língua) e planejamento de status (planejamento relacionado à atribuição de funções para a língua)”, criada por Kloss, em 1969 (SOUSA; PONTE; SOUSA-BERNINI, 2019, p. 09). Em "Language planning and social change ${ }^{4}$, , Robert Cooper (2000) defende que política e planejamento linguístico são termos similares e remetem a uma institucionalização do uso das línguas em sociedade. O pesquisador, tendo em vista a definição de planejamento linguístico criada por Haugen, em 1959, enumera doze definições para o termo "language planning", , de autoria de diversos estudiosos. A seguir, citamos três destas definições ${ }^{6}$ que nos parecem interessantes:

i. We do not define planning as an idealistic and exclusively linguistic activity but as a political and administrative activity for solving language problems in society ${ }^{7}$ (COOPER, 2000, p. 30).

ii. The term language planning refers to the organized pursuit of solutions to language problems, typically at the national level ${ }^{8}$ (COOPER, 2000, p. 30).

iii. Language policy-making involves decisions concerning the teaching and use of language, and their careful formulation by those empowered to do so, for the guidance of others ${ }^{9}$ (COOPER, 2000, p. 30).

Para Cooper, as três definições citadas anteriormente, bem como as outras doze citações enumeradas no seu estudo, devem ser discutidas levando em conta "Who plans what for whom and how?"10 (COOPER, 2000, p.31). Ou seja, não se pode compreender o planejamento linguístico sem problematizar quem, o quê, para quem e como as políticas

\footnotetext{
${ }^{4}$ Planejamento linguístico e mudança social (Todas as traduções são de nossa responsabilidade).

${ }^{5}$ Planejamento linguístico.

${ }^{6}$ A primeira definição citada por Cooper (2000) é de autoria de Jernudd e Das Gupta (1971). O segundo conceito advém dos estudos de Gorman (1973) e, por fim, a terceira citação é oriunda de Prator apud Markee (1986). Para mais informações, consultar o texto de Cooper (2000).

${ }^{7}$ Não definimos o planejamento como uma atividade exclusivamente linguística e idealista, mas como uma atividade política e administrativa para resolver problemas de linguagem na sociedade (COOPER, 2000, p. 30).

${ }^{8} \mathrm{O}$ termo planejamento linguístico faz referência a uma busca sistematizada de soluções para os problemas linguísticos, normalmente em nível nacional (COOPER, 2000, p. 30).

9 A formulação de políticas linguísticas envolve decisões referentes ao ensino e uso da língua em sua formulação meticulosa por aqueles em posição de fazê-lo, sendo estes modelos utilizados para orientar outras pessoas (COOPER, 2000, p. 30).

${ }^{10}$ Quem planeja, o quê, para quem e como (COOPER, 2000, p. 31).
} 
linguísticas são elaboradas. Nesse sentido, o autor ainda questiona o fato de que algumas definições tradicionais restringem as políticas linguísticas às atividades governamentais, pois "some definitions restrict language planning to activities under taken by governments, government-authorized agencies, or other authoritative bodies, i.e., organizations with a public mandate for language regulation" (COOPER, 2000, p. 31) $)^{11}$.

Desse modo, o autor citado no parágrafo anterior opta por uma definição de PL que não se limita ao meio governamental e que considera como política (linguística) um conjunto de ações desenvolvidas por instituições não governamentais, mencionando, por exemplo, uma Sinagoga de Jerusalém, cuja congregação é composta por imigrantes israelenses e norte-americanos. Parte dos fiéis fala inglês e outros só se comunicam em hebraico. Para resolver o problema de comunicação, foi adotada pela Sinagoga uma PL que permitia que a pregação fosse compreendida tanto pelos imigrantes norte-americanos, quanto pelos israelenses. Assim, o autor em questão detalha a sua concepção de PL com os seguintes termos:

Language planning, in my view, is directed not only towards aggregates at the level of the society or state and not only at larger aggregates which cut across national boundaries but also at smaller aggregates - ethnic, religious, occupational, and so on. But how small can such aggregates be, and still be the objects of language planning? Must we confine the object of our definition to groups so large that their members cannot interact with all other members of the group but only with a subset of the members? If we confine language planning to such "open networks" we would have to exclude small groups such as schools, classrooms, neighborhood and village associations, trade union branches, 'women's lib'consciousness raising circles, local professional and occupational organizations, religious congregations, and branches of fraternal associations. But the communicative behavior of such small groups is often the object of explicit attention ${ }^{12}$ (COOPER, 2000, p. 36).

\footnotetext{
${ }^{11}$ Algumas definições restringem o planejamento linguístico a atividades que são de responsabilidade dos governos, das agências autorizadas pelo governo ou outros órgãos respeitados, isto é, organizações publicamente autorizadas para a regulamentação da linguagem (COOPER, 2000, p. 31).

${ }^{12} \mathrm{O}$ planejamento linguístico, em minha opinião, é direcionado não apenas ao grupo de pessoas no nível da sociedade ou do Estado, e não apenas a grupos maiores que ultrapassam as fronteiras nacionais, mas também a grupos menores - étnicos, religiosos, profissionais etc. Mas qual o tamanho mínimo destes grupos, para que possam ser objetos de planejamento linguístico? Devemos limitar o objeto por nós definido a grupos tão grandes que seus membros não possam interagir com todos os outros membros do grupo, mas apenas com um subconjunto deles? Se limitarmos o planejamento linguístico a essas "redes abertas", teremos de excluir pequenos grupos, como escolas, salas de aula, associações de bairros e pequenas comunidades, filiais sindicais, círculos de conscientização da "liberdade das mulheres", organizações profissionais e ocupacionais locais, congregações religiosas e ramos de associações fraternas. Entretanto, o comportamento
} 
Ao defender a ideia de que as PL influenciam e modificam o comportamento das pessoas no que diz respeito à aquisição e ao uso dos idiomas no meio social, o referido estudioso não limita as decisões tomadas em torno do planejamento linguístico (ou das políticas linguísticas) aos grupos hegemônicos da sociedade, tais como as organizações governamentais, como dito anteriormente. Não se pode, portanto, nesta perspectiva, excluir do conjunto de decisões linguísticas, por exemplo, as escolas e as pequenas associações que utilizam as línguas no meio social.

Tratando ainda de um desenvolvimento do conceito de planejamento e política linguística, Sousa, Ponte e Sousa-Bernini (2019, p. 09) estabelecem uma divisão do termo em três etapas. A primeira se relaciona com a criação do conceito de planejamento linguístico por Haugen, quando no início dos anos 1960 predominava o estruturalismo nas ciências sociais, além da emancipação e formação de Estados-nação no mundo moderno. Ainda, de acordo com as autoras, a segunda etapa compreende os anos 1970 e 1980 e se caracteriza pelo advento de uma sociolinguística crítica e por um questionamento ao paradigma positivista vigente até então.

Conforme as estudiosas, a terceira etapa é iniciada nos anos 1980 e permanece até os dias atuais se singularizando pela defesa dos chamados direitos linguísticos. Neste período, a teoria crítica "desenvolveu uma corrente dentro do campo denominado "política linguística crítica' que explora as ideologias que fundamentam as políticas linguísticas, bem como os fatores históricos e estruturais" (SOUSA; PONTE; SOUSA-BERNINI, 2019, p. 17) que dão sustentabilidade a um mundo marcado pela desigualdade desconsiderando, inclusive, uma política dos direitos linguísticos.

Neste artigo, concentramo-nos na terceira etapa, ou seja, aquela que pensa em uma política linguística de base crítica, alicerçada pelas demandas do mundo contemporâneo. Nesse sentido, Oliveira (2016) estabelece uma distinção entre quem faz e quem estuda PL. De modo genérico, podemos entender que instituições governamentais e autoridades oficiais são os principais organismos que produzem leis, normas e documentos que regulam as línguas a partir de políticas oficiais, mas não os únicos. Acreditamos, assim, que organismos governamentais produzem, portanto, macropolíticas linguísticas que se

comunicativo de pequenos grupos como esses é frequentemente objeto de atenção explícita (COOPER, 2000, p. 36). 
caracterizam por um caráter de oficialidade. Por outro lado, as PL são estudadas pela comunidade acadêmica, como linguistas, linguistas aplicados, pedagogos e cientistas sociais, e este grupo também pode criar novas micropolíticas que se contraponham às macropolíticas implementadas pelo Estado - e que muitas vezes podem desconsiderar as demandas da sociedade.

Essa divisão proposta por Oliveira (2016) não é oposta à compreensão de PL nos estudos de Cooper (2000). Ainda que, principalmente nos anos 1990, seja recorrente o planejamento linguístico por instituições governamentais, o que podemos perceber, desde os anos 2000, é que outros grupos também se ocuparam das políticas linguísticas a partir de um movimento duplo: o de questionar macropolíticas e, ao mesmo tempo, propor micropolíticas que podem obter um caráter oficial, transformando-se em políticas linguísticas que gozam de um status de oficialidade, como exposto na citação a seguir:

\begin{abstract}
Muita gente que ouve a expressão 'políticas linguísticas' pela primeira vez pensa em algo solene, formal, oficial, em leis e portarias, em autoridades oficiais, e pode ficar se perguntando o que seriam leis sobre línguas. De fato, há leis sobre línguas [...], mas as políticas linguísticas também podem ser menos formais - e nem passar por leis propriamente ditas. Em quase todos os casos, figuram no cotidiano, pois envolvem como propõe Spolsky [...], não só a gestão da linguagem, mas também as práticas de linguagem, e as crenças e valores que circulam a respeito delas (GARCEZ; SCHULZ, 2016, p. 01).
\end{abstract}

De forma bastante didática, os autores defendem a ideia de que as PL foram entendidas, exclusivamente, como um conjunto de leis, normas, resoluções e documentos prescritivos que legislam sobre o uso da língua, o que remete a uma visão reduzida do conceito.Outrossim, as políticas linguísticas se materializam no dia a dia das práticas de linguagem e podem ser elaboradas por sujeitos que não representam organizações oficiais. Nesse sentido, concordamos com Garcez e Schulz (2016) quando mencionam que ações minoritárias também podem se constituir em PL. A este respeito, Ponte (2010, p. 267) afirma que "la intervención lingüística no se da solamente por medio de leyes o medidas constructivas, la historia nos muestra que gestos políticos son muy eficaces"13 Além disso, a autora também chama a atenção para as línguas enquanto instrumentos de poder:

\footnotetext{
${ }^{13}$ a intervenção linguística não ocorre apenas por meio de leis ou de medidas construtivas, a história nos mostra que gestos políticos são muito eficazes (PONTE, 2010, p. 267).
} 
A pesar de que se pueda pensar que la política lingüística está relacionada únicamente a situaciones postcoloniales o a la defensa de las lenguas minoritarias, es necesario entender que dichas situaciones sirven únicamente como hechos impulsores, una vez que la relación entre lengua y vida social está presente en cualquier sociedad y en cualquier época (PONTE, 2010, p. 268) ${ }^{14}$.

O contexto revelado pela estudiosa pode exemplificar a importância das políticas linguísticas em torno da difusão do espanhol no Brasil. No caso particular da língua castelhana, ao se defender o ensino desse idioma no nosso país, podemos mobilizar um conjunto de justificativas políticas que amparam a importância de aprender espanhol hoje, mas também podemos dizer que a relação entre língua e vida social (PONTE, 2010) encontra-se permanentemente intricada com o ensino da língua espanhola nas escolas brasileiras, uma vez que geograficamente estamos marcados pelo contato entre o português e o espanhol (além de tantas outras línguas faladas na América Latina), constituindo a nossa identidade latino-americana, como já mencionado ao longo desse artigo.

Evidentemente, não estamos dizendo que as PL oficiais não são importantes. Nesse sentido, poderíamos dizer que o espanhol ganha notoriedade no Brasil em três momentos. Primeiramente quando os Parâmetros Curriculares Nacionais - Ensino Médio (2000) trouxeram a seguinte problematização:

Nesse sentido vários pontos merecem atenção. Um deles diz respeito ao monopólio linguístico que dominou nas últimas duas décadas em especial nas escolas públicas. Sem dúvida, a aprendizagem da Língua Inglesa é fundamental no mundo moderno, porém, essa não deve ser a única possibilidade a ser oferecida ao aluno. Em contrapartida, verificouse nos últimos anos, um crescente interesse pelo estudo do castelhano. De igual maneira, entendemos que tampouco deva substituir-se um monopólio linguístico por outro (BRASIL, 2000, p. 27).

De modo geral, notava-se uma preocupação dos Parâmetros com a possibilidade de oferta de mais de uma língua estrangeira na educação nacional e com a desconstrução de

\footnotetext{
${ }^{14}$ Ainda que se possa pensar que a política linguística está relacionada unicamente a situações pós-coloniais ou à defesa das línguas minoritárias, é necessário entender que ditas situações servem unicamente como fatos impulsores, uma vez que a relação entre língua e vida social está presente em qualquer sociedade e em qualquer época (PONTE, 2010, p. 268).
} 
um monopólio linguístico voltado para o inglês. O segundo momento diz respeito à aprovação da Lei nacional $\mathrm{n}^{\circ} 11.161 / 2005$, sendo esta a principal responsável por um movimento de difusão do espanhol no nosso país, além de propiciar certa ${ }^{15}$ pluralidade linguística, no momento em que se oficializava a presença de duas línguas nas escolas do nosso país - sendo importante criticar o caráter facultativo de matrícula do aluno na disciplina de língua castelhana. O terceiro evento diz respeito à publicação das Orientações Curriculares Nacionais (OCN) para o ensino médio (2006) que, ao tratar dos conhecimentos de língua estrangeira, trazia um capítulo específico denominado “Conhecimentos de espanhol”, demonstrando a importância da disciplina supracitada.

Quando avaliamos os cem anos da presença da língua espanhola na realidade brasileira (GUIMARÃES, 2011), pontuamos que diversas leis e documentos oficiais tratam do ensino desta língua no Brasil. Contudo, é fundamental frisar que políticas linguísticas não são propostas exclusivamente por organizações governamentais ou instituições hegemônicas. Grupos de professores e estudantes também podem questionar as macropolíticas, criando micropolíticas que, posteriormente, podem se constituir em políticas oficiais. Como forma de ilustrar esta ideia, nas próximas seções deste artigo nos centraremos em algumas leis municipais e estaduais, no contexto nordestino, que comprovam que as políticas linguísticas podem ser planejadas por grupos de resistência.

\section{POLÍTICAS LINGUÍSTICAS ACERCA DO ENSINO DE ESPANHOL A PARTIR DA REVOGAÇÃO DA LEI No11.161/2005}

No nosso artigo, quando defendemos a ideia de que as macropolíticas linguísticas implementadas pelo Estado podem ser questionadas e que novas PL de resistência podem surgir, queremos mostrar a importância da organização social de professores e alunos de espanhol, por meio das associações, por exemplo, para reverter o quadro de monolinguismo que atinge o atual cenário educacional. Assim, trataremos, a partir de

\footnotetext{
${ }^{15}$ Utilizamos a expressão "certa pluralidade" porque acreditamos que não apenas o inglês e o espanhol devam ser ofertados na escola pública. Em uma entrevista para a Revista Afluente, a professora Denise Lino de Araújo defendia que outras línguas deveriam estar presentes no nosso sistema educativo: "Observo que recuamos quando só temos como opção oficial o ensino de inglês. Lamento muito que não tenhamos no ENEM a opção de francês ou japonês, por exemplo. Línguas estrangeiras fazem falta na escola. O contato com elas não apenas amplia o horizonte cultural, como faz pensar sobre a própria língua materna" (COSTA JUNIOR, 2018, p. 146).
} 
agora, de um conjunto de PL de resistência que se opõe aos retrocessos educacionais em voga desde o golpe político operado contra Dilma Rousseff, com ampliação no governo de Michel Temer e forte tentativa de desmonte ${ }^{16}$ da educação pública, de qualidade e para todos a partir da chegada de Jair Bolsonaro à presidência.

Tendo em consideração as ações políticas mais recentes que alteraram a realidade do ensino de espanhol no Brasil, vale relembrar, afim de contextualização, que a Medida Provisória (doravante MP) $\mathrm{n}^{\circ}$ 746, de 22 de setembro de 2016, editada no Congresso Nacional do país, transformando-se, no ano seguinte, na Lei de Reforma do Ensino Médio - Lei n $n^{\circ}$ 13.415, de 16 de fevereiro de 2017 -, gerou uma sensação de incertezas sob os membros da comunidade escolar. Isto se deu porque não houve um amplo debate sobre essas mudanças para a reforma educacional, sobretudo, com os professores e pesquisadores especializados das diversas áreas educacionais, nem com os alunos e os demais membros da sociedade que fazem parte do entorno da comunidade escolar ${ }^{17}$.

Sobre tal contexto de mudanças políticas que alteraram diretamente as bases do ensino no país, estamos de acordo com Silva (2018) que defende que a aprovação desta lei se deu de forma antecipada e apressada. Isto demonstra que muitas das alterações presentes no documento, como a invisibilidade do ensino de língua espanhola, estão amparadas por decisões do âmbito mais político-econômico, visando um mercado neoliberal, do que propriamente escolhas educacionais e linguísticas,considerando questões de identidade, afetividade, cidadania, entres outros, inclusive de interesse comercial, como é o caso que citamos anteriormente de fortalecer as relações com os países vizinhos a partir do MERCOSUL.

A MP de 2016, que não revoga apenas o ensino de espanhol, mas afeta tantas outras disciplinas como artes, educação física, filosofia e sociologia, não condiz com as políticas educacionais democráticas discutidas até então pelos especialistas da área. Conclui-se, pois, que tal medida surgiu numa conjuntura de pós-golpe presidencial,

\footnotetext{
${ }^{16}$ Vale lembrar que a agenda política de Jair Bolsonaro para a educação é o desmonte do ensino público. Ricardo Vélez Rodriguez, Abraham Weintraub, Carlos Decotelli e Milton Ribeiro são nomes que representam várias tentativas de precarização, desmonte e privatização da escola pública, operadas por um governo envolvido com milicianos, pastores acusados de corrupção, empresários sonegadores de impostos, dentre outros.

${ }^{17}$ Ressaltamos que uma mudança curricular tão profunda precisaria de uma ampla discussão democrática com a sociedade e, acima de tudo, necessitaria de tempo hábil para sua implantação e consolidação no espaço de um governo, o que não ocorreu em relação à MP de 2016.
} 
formulada num governo impopular e antidemocrático que não consultou efetivamente os agentes - professores, alunos e comunidade civil e acadêmica, em geral, - que deveriam estar envolvidos nesse enorme projeto educacional.

Ainda, a partir da MP $n^{\circ} 746 / 2016$, recapitulamos que começou a haver uma mudança de rumos do ensino no Brasil, quando deixamos de ser um país com oferta plurilíngue, cuja escolha da língua moderna estrangeira ficava a cargo da comunidade escolar, para seguir um paradigma de oferta monolíngue na qual o inglês passou a ser a única língua oferecida nas escolas de forma obrigatória. O espanhol assumiu agora um caráter optativo de oferta, portanto, não cabe mais ao aluno escolher qual idioma estrangeiro estudar. Outras línguas, como o italiano, o francês e o alemão, importantes devido ao fluxo migratório em determinadas regiões do país, por exemplo, sequer têm espaço nos documentos educacionais prescritivos do Brasil e isso já acontecia deste antes da MP.

A partir da Lei do Espanhol, durante 11 anos (entre 2005 e 2016), houve um período em que uma série de medidas de fortalecimento das políticas linguísticas para o ensino deste idioma ocorreram no país. É verdade que nem todas as ações provenientes desta lei foram efetivadas de maneira uniforme em toda a nação; no entanto, se consistia como um grande respaldo na luta pela integração entre os países latino-americanos, a partir do ensino de espanhol aos brasileiros, único país no continente americano a ter o português como idioma oficial.

Em virtude das mudanças que ocorreram e vem ocorrendo, desde 2016, no tocante ao ensino de língua espanhola no Brasil, ações de resistência vêm levando ao desenvolvimento de micro e de macropolíticas públicas para a permanência deste idioma nas escolas federais, dos estados e dos municípios brasileiros, além das instituições privadas. Dentre elas, podemos destacar como pioneiras nessas PL para a permanência da língua espanhola no currículo, três ações de resistência:

\section{- Criação e expansão do Movimento Fica Espanhol}

Em decorrência dessas reformas inauguradas a partir da MP n ${ }^{\circ} 746 / 2016$, se inicia uma infinidade de lutas coletivas para a permanência do ensino de espanhol nas escolas de todo Brasil, como a criação do Movimento Fica Espanhol, que ganhou destaque a partir 
das redes sociais com professores do Rio Grande do Sul, levando à aprovação de uma proposta de emenda constitucional estadual que assegurou a oferta obrigatória da língua espanhola nas escolas regulares do estado em questão. Este movimento, inclusive, está historicizado a partir da publicação do livro “\#FicaEspanhol no RS: Políticas Linguísticas, Formação de Professores, Desafios e Possibilidades" (2019), organizado por Angelise Fagundes, Denise Pérez Lacerda e Giane Rodrigues dos Santos. Desde então, o movimento vem se expandindo para os diferentes estados e municípios do Brasil e recebendo apoio de artistas, promotores culturais, políticos, formadores de opinião entre outros setores da sociedade na luta pela manutenção do oferecimento obrigatório da língua espanhola nas escolas, para aqueles que optarem por aprender este idioma.Na Paraíba e em Rondônia, por exemplo, a luta de professores e associações docentes foi fortalecida pelo movimento em questão e, por meio da aprovação de projetos de lei, esses estados também garantiram a oferta do idioma.

\section{- Abertura e reativação de associações de professores e de estudantes de espanhol}

Uma das formas de fortalecer as lutas dos movimentos de resistência e a construção de políticas públicas que possibilitem a oferta do ensino de espanhol se deu através da abertura e reativação de associações de professores e estudantes. A este respeito, recomendamos a leitura do trabalho de Paulino (2019), intitulado "A Associação de Professores de Espanhol do Estado da Paraíba (APEEPB) como agente de Política Linguística e a sua relação com a Lei Estadual 11.191/2018”, cuja discussão se aproxima do debate proposto em nosso artigo, tratando especificamente da associação paraibana.

A maioria das associações de professores de espanhol do Nordeste foram fundadas entre o final dos anos 80 e começo dos anos 90. Reativadas, algumas, a partir de 2016. Ao todo, são vinte e quatro associações de professores de espanhol, espalhadas pelas cinco regiões do país, conforme dados divulgados no XVIII Congresso Brasileiro de Professores de Espanhol, em novembro de 2019, na Universidade Federal do Amazonas (UFAM). Dos nove estados do Nordeste, em oito há associações ativas, atualmente. Exceto no Maranhão, estado no qual, durante o processo de escrita deste trabalho, a associação encontra-se desativada. 
Estivemos em contato, via e-mails, sites oficiais, redes sociais e através de mensagens eletrônicas, com membros destas associações que nos facilitaram informações sobre alguns dos dados que apresentamos neste artigo, a seguir. Para não nos estendermos, citemos somente as associações ativas na região Nordeste, que é tema deste artigo:

- Alagoas: Associação de Professores de Espanhol do Estado de Alagoas - APEEAL. Fundada em 3 de maio de 1991.

- Bahia: Associação de Professores de Espanhol do Estado da Bahia - APEEBA. Fundada em 13 de fevereiro de 1989.

- Ceará: Associação dos Professores de Espanhol do Estado do Ceará - APEECE. Fundada em 21 de abril de 1989. Reativada em 6 de dezembro de 2019.

- Paraíba: Associação de Professores de Espanhol do Estado da Paraíba - APEEPB. Fundada em 1989. ${ }^{18}$

- Pernambuco: Associação de Professores de Espanhol do Estado de Pernambuco APEEPE. Fundada em 29 de março de 1989.

- Piauí: Associação de Professores de Espanhol do Estado da Piauí - APEEPI. Fundada em 29 de novembro de 2005.

- Rio Grande do Norte: Associação de Professores e Estudantes de Língua Espanhola do Rio Grande do Norte - APELE-RN. Fundada em 6 de agosto de 2010. A APELE-RN esteve inativa ${ }^{19}$ entre 2012 e 2016.

- Sergipe: Associação de Professores de Espanhol do Estado de Sergipe - APEEPE. Fundada em 2011 e reativada em $2015 .^{20}$

\section{- $\quad$ Projetos de lei estaduais e municipais para o ensino de espanhol}

A partir das lutas coletivas dos movimentos de resistência tanto das associações como de ações encabeçadas por coletivos de professores de espanhol de universidades, escolas e/ou Institutos Federais, por exemplo,além das ações dos membros do Movimento Fica Espanhol, ampliou-se as implantações de leis estaduais e municipais de ensino deste

\footnotetext{
${ }^{18}$ Não encontramos informações detalhadas sobre o dia e o mês de fundação da APEEPB.

19 No caso da APELE-RN, se entende por "inativa" o fato de a eleição da diretoria ter deixado de ser arquivada em cartório.

${ }^{20}$ Não encontramos informações detalhadas sobre o dia e o mês de fundação da APEEPE.
} 
idioma em todo Brasil, pós-revogação da Lei n ${ }^{\circ} 11.161 / 2005$.

Do papel da nossa região, neste momento de resistência para manter a pluralidade linguística e cultural em nosso país, trataremos com mais detalhes no tópico a seguir, quando mencionaremos alguns projetos de lei acerca do ensino de espanhol nas escolas de diferentes estados do Nordeste. Nesse sentido, já podemos citar o pioneirismo nordestino, através do que vem acontecendo na Paraíba, a partir da aprovação do Projeto de Lei $\mathrm{n}^{\circ}$ 11.191/2018 que mantém, em nível estadual, o que já havia sido disposto na Lei do Espanhol, em nível nacional entre 2005 e 2016, com a Lei n 11.161/2005.

\section{O NORDESTE BRASILEIRO NOS MOVIMENTOS DE RESISTÊNCIA PARA A MANUTENÇÃO DO ESPANHOL NAS ESCOLAS: TRAMITAÇÃO E APROVAÇÃ̃O DE PROJETOS DE LEI}

Não há dúvidas, que, aos estados do Nordeste do Brasil, cabe lugar de destaque nas ações e políticas de resistência pela permanência do espanhol nas escolas com o objetivo de fortalecer um contexto de ensino multicultural e plurilíngue, sendo o livro "Espanhol no Nordeste: espaços de resistência, criação e transformação" (NOGUEIRA; BAPTISTA, 2018), um exemplo desta discussão. Neste sentido, vale a pena citar algumas das políticas de resistência rumo à constituição de políticas linguísticas plurilíngues que garantam a manutenção do ensino de espanhol nesses estados.

No que diz respeito ao estado de Alagoas, em 16 de abril de 2019, foi publicada, no site de Sistema de Apoio ao Processo Legislativo da Assembleia Legislativa alagoana a indicação ${ }^{\circ} 116 / 2019^{21}$, de autoria do deputado Bruno Toledo (PROS), que solicita a implantação da Língua Espanhola como disciplina escolar da grade curricular do Ensino Médio da rede pública.

Na Bahia, sobre o ensino do espanhol pós-reforma do Ensino Médio, os membros da associação de professores de espanhol tiveram várias reuniões com a Secretaria de Educação (SEC) e na Assembleia Legislativa da Bahia (ALBA), porém não obtiveram respostas plausíveis dos líderes governamentais. Mediante consulta diretamente à atual diretoria da associação baiana, recebemos a boa notícia de que seus membros "continuam

\footnotetext{
21 Assembleia Legislativa de Alagoas, 2019. Disponível em: $<$ https://sapl.al.al.leg.br/media/sapl/public/materialegislativa/2019/4780/protocolo_20190417_090348.pdf > Acesso em: 21 mar. 2020.
} 
na luta" buscando o diálogo com a classe política para reverter essa situação do ensino de espanhol no estado.

Já no Ceará, a associação dos professores de espanhol foi recentemente reativada, no final de 2019, e seus membros encontram-se em debate com a classe política do estado para as próximas medidas a serem tomadas, de manutenção do ensino do idioma nas escolas. Desse modo, presidida pelo deputado Queiroz Filho (PDT), a Comissão de Educação na Assembleia Legislativa do Ceará deliberou, no ano passado, o Projeto de Lei $\mathrm{n}^{\circ} 540 / 2019^{22}$ que dispõe sobre aulas de língua espanhola na grade curricular do Ensino Médio da rede estadual de educação. De acordo com o projeto, os profissionais que poderão lecionar esta disciplina deverão ser formados em Licenciatura Plena em LetrasEspanhol ou em Licenciatura Plena em Letras com dupla habilitação em EspanholPortuguês. No caso, a disciplina deverá ter carga horária mínima de duas horas aula semanais em cada uma das três séries do Ensino Médio.

Na Paraíba, foi publicada, no dia 5 de maio de 2018, uma lei no Diário Oficial do Estado (DOE) que prevê a oferta da disciplina de língua espanhola na grade curricular da rede estadual de ensino. Conforme o dispositivo ${ }^{\circ} 11.191 / 2018^{23}$, de autoria do deputado Anísio Maia (PT), a disciplina passa a ser facultativa nas escolas públicas estaduais de Ensino Fundamental e, conforme o que já vinha sendo praticado nesse estado torna-se obrigatória no Ensino Médio. Destaca-se também, o pioneirismo de leis municipais acerca do ensino de espanhol no Ensino Fundamental. Para citar apenas um exemplo, mencionamos a Lei $n^{\circ} 321 / 2017^{24}$ que versa sobre a obrigatoriedade do ensino da língua espanhola nas escolas do município de Areial (PB).

Em Pernambuco, o espanhol se manteve a partir da oferta nos NEL (Núcleo de Estudos em Línguas) da rede estadual de ensino que dispõe de trinta e quatro (34) núcleos distribuídos em todo o estado. Além do espanhol, são oferecidos curso de alemão, francês e inglês. No ano passado, foi encaminhado o Projeto de Lei $n^{\circ} 235 / 2019^{25}$, que dispõe

22 Projeto de lei $\quad \mathrm{N}^{\circ} \quad 540 / 19, \quad 2019 . \quad$ Disponível $\quad$ em:
$<$ https://www2.al.ce.gov.br/legislativo/tramit2019/p1540_19.htm>. Acesso em: 21 mar. 2020.

23 Diário do Poder Legislativo - Estado da Paraíba, 2018. Disponível em: <http://www.al.pb.leg.br/wpcontent/uploads/2018/09/DPL-05.09.2018.pdf> Acesso em: 21 mar. 2020.

$24 \quad$ Fonte: <http://areial.pb.gov.br/portal/projeto-de-lei-de-iniciativa-popular-e-aprovado-na-camara-emunicipio-ira-oficializar-a-lingua-espanhola-na-rede-de-ensino/> Acesso em: 21 mar. 2020.

${ }^{25}$ Assembleia Legislativa do Estado de Pernambuco. Projeto de Lei Ordinária 235/2019, 2019. Disponível em: <http://www.alepe.pe.gov.br/proposicao-texto-completo/?docid=4584\&tipoprop=p >. Acesso em: 21 
sobre a obrigatoriedade da implantação da disciplina de língua espanhola na grade curricular das escolas do Ensino Médio na rede estadual de ensino, à Assembleia Legislativa do Estado de Pernambuco (ALEPE); no entanto, o PL foi embargado.

No Piauí, um projeto de lei apresentado na Assembleia Legislativa do Piauí (ALEPI) quer tornar obrigatório o ensino da língua espanhola no Ensino Médio nas escolas da rede estadual e privada do Estado. A proposta foi apresentada pelo deputado estadual Fábio Novo (PT) e estabelece que a disciplina seria facultativa no Ensino Fundamental. No caso do Ensino Médio, obrigatória e com carga horária de duas horas semanais.

No estado do Rio Grande do Norte, ainda não houve avanço, junto à classe política, rumo a um PL em nível estadual, embora discussões venham acontecendo no intuito de solucionar esse impasse ${ }^{26}$. Há, no entanto, duas leis já aprovadas, em nível municipal. Uma é a da cidade de Currais Novos, a Lei $\mathrm{n}^{\circ} 3.466^{27}$, de 16 de dezembro de 2019, que dispõe, nos currículos do Ensino Fundamental II e da modalidade EJA, sobre a inclusão obrigatória do estudo do idioma aqui em questão. E, em Mossoró, encabeçadas por professores da Universidade do Estado do Rio Grande do Norte (UERN), estão ocorrendo reuniões com a Secretaria de Educação. Foi apresentada uma proposta de implantação que retoma o Projeto de Lei $\mathrm{n}^{\circ} 3173 / 2014^{28}$ do vereador professor Francisco Carlos(PP). O projeto em questão já havia sido aprovado pela Câmara Municipal de Mossoró no final do ano legislativo de 2013 e dispõe sobre a oferta do ensino de língua espanhola nas escolas da rede municipal de ensino desta cidade, nas turmas do $6^{\circ}$ ao $9^{\circ}$ ano do Ensino Fundamental.

Por último, porém não menos importante, no que se refere às políticas linguísticas para a manutenção do ensino de espanhol, por meio da Secretaria de Estado da Educação (SEED), em Sergipe, se manteve a oferta do espanhol na grade curricular do Programa

\footnotetext{
mar. 2020.

${ }^{26}$ Assembleia Legislativa do Rio Grande Do Norte. Legislativo Discute Obrigatoriedade da Língua Espanhola Nas Escolas Estaduais, 2019. Disponível em: $<$ http://www.al.rn.gov.br/portal/noticias/13581/legislativo-discute-obrigatoriedade-da-lngua-espanhola-nasescolas-estaduais >. Acesso em: 21 mar. 2020.

${ }^{27}$ Leis municipais - Currais Novos. Lei $N^{\circ} 3.466$ de 16 de dezembro de 2019. 2019. Disponível em: <encurtador.com.br/anvP3 >. Acesso em: 21 mar. 2020.

28 Tivemos acesso à Lei $\mathrm{n}^{\circ} 3173 / 2014$, a partir do arquivo digitalizado que nos foi enviado por professores da UERN que encabeçam a implantação da lei no município de Mossoró-RN.
} 
Ensino Médio Inovador - ProEM ${ }^{29}$ (integral). A manutenção da língua espanhola em Sergipe é resultado da luta do Movimento Fica Espanhol junto à deputada estadual Ana Lula (PT), quando em audiência pública na Assembleia Legislativa, em 04 de setembro de $2018^{30}$, decidiu-se sobre a oferta do castelhano nas escolas sergipanas. Mais recentemente, em março 2019, o secretário de Estado da Educação, do Esporte e da Cultura (Seduc), professor Josué Modesto (Sem partido) recebeu em seu gabinete professores do movimento e garantiu que o espanhol permaneceria na rede estadual. Atualmente, encontra-se em tramitação a Proposta de Emenda Constitucional (PEC) n ${ }^{\circ} 3 / 2019^{31}$ para a inclusão do espanhol no Ensino Médio de forma regular.

\section{CONSIDERAÇÕES FINAIS}

Embora o que se espera, cada vez mais, enquanto partícipes sociais, é que avancemos em direção a realidades multilíngues, a política linguística que impera hoje no Brasil, a partir dos mais recentes documentos oficiais que estabelecem as diretrizes nacionais para o ensino, promove um retrocesso ao voltar a pautar-se em ideais monolíngues com a imposição do ensino de inglês como único idioma estrangeiro obrigatório, deixando o espanhol e outras línguas estrangeiras modernas relegadas a um espaço periférico.

Considerando esse retrocesso educacional do contexto brasileiro, traçamos, neste artigo, uma discussão sobre políticas linguísticas e ensino de língua espanhola, partindo da defesa de que a presença do espanhol no país se justifica mais do que por interesses econômicos, devido à relevância da integração latino-americana que fortalece nossa necessidade de contato com os demais países da América Latina,tendo em vistao reconhecimento da pluralidade da identidade cultural-linguística, seja em língua materna, seja na língua dos países vizinhos.

\footnotetext{
${ }^{29}$ Tal programa do Ministério da Educação - MEC foi criado no intuito de promover o redesenho e a flexibilização do currículo nas escolas de ensino médio, pois possibilita a realização de uma prática pedagógica mais dinâmica, contextualizada, interdisciplinar e, sobretudo, que atenda ao projeto de vida dos estudantes (SANTOS, 2018).

${ }^{30}$ Assembleia Legislativa do Estado de Sergipe. Audiência defende Língua Espanhola na Educação Pública. 2018. Disponível em: <https://al.se.leg.br/audiencia-defende-lingua-espanhola-na-educacao-publica/>. Acesso em: 21 mar. 2020.

${ }^{31}$ Tivemos acesso a PEC $\mathrm{n}^{\circ} 3 / 2019$, a partir do arquivo digitalizado que nos foi enviado pela direção do Movimento Fica Espanhol de Sergipe.
} 
Assim, ao ressaltar o caráter político do ensino do espanhol no país, discorremos sobre o conceito de políticas linguísticas e contribuímos para o debate trazendo os conceitos de micropolíticas e macropolíticas linguísticas. Também mencionamos algumas das mais atuais políticas de resistência para a manutenção do ensino de espanhol no país, mais especificamente, a nível estadual e/ou municipal, oficializando o ensino do castelhano no Nordeste brasileiro.

Como micropolíticas de resistência, apresentamos a luta de professores e estudantes de espanhol de diferentes instituições de ensino, vinculados ao Movimento Fica Espanhol bem como os das associações de professores, culminando em políticas estaduais e municipais que levaram à elaboração de leis oficias para a implantação e/ou permanência do espanhol nas escolas da região, o que se contrapõe à força de macropolíticas nacionais que têm como finalidade promover uma desintegração regional.

\section{REFERÊNCIAS}

BRASIL. Lei $n^{o}$. 9.394, de 20 dez. 1996. Estabelece a Lei de Diretrizes e Bases da Educação Nacional - LDB, 1996.

BRASIL. Parâmetros Curriculares Nacionais - Ensino Médio. Brasília: MEC/SEF, 2000.

BRASIL. Lei $n^{o}$. 9.394, de 05 ago. 2005. Dispõe sobre o ensino da língua espanhola, 2005.

BRASIL. Orientações Curriculares para o Ensino Médio. Brasília: MEC/SEB, 2006.

BRASIL. Medida provisória $n^{o}$ 746, de 22 set. 2016. Institui a Política de Fomento à Implementação de Escolas de Ensino Médio em Tempo Integral, altera a Lei $n^{\circ}$ 9.394, de 20 de dezembro de 1996, que estabelece as diretrizes e bases da educação nacional, e a Lei $\mathrm{n}^{\circ} 11.494$ de 20 de junho 2007, que regulamenta o Fundo de Manutenção e Desenvolvimento da Educação Básica e de Valorização dos Profissionais da Educação, e dá outras providências, 2016.

BRASIL. Lei $n^{\circ}$ 13.415, de 16 fev. 2017. Altera as Leis ${ }^{\circ}{ }_{-9} 9.394$, de 20 de dezembro de 1996, que estabelece as diretrizes e bases da educação nacional, e 11.494, de 20 de junho 2007, que regulamenta o Fundo de Manutenção e Desenvolvimento da Educação Básica e de Valorização dos Profissionais da Educação, a Consolidação das Leis do Trabalho CLT, aprovada pelo Decreto-Lei $n^{\circ} 5.452$, de $1^{\circ}$ de maio de 1943, e o Decreto-Lei $n^{\circ} 236$, de 28 de fevereiro de 1967; revoga a Lei $\mathrm{n}^{\circ} 11.161$, de 5 de agosto de 2005; e institui a Política de Fomento à Implementação de Escolas de Ensino Médio em Tempo Integral, 2017. 
CARVALHO, J. P. Contrastes e reflexões sobre o ensino de espanhol em escolas públicas do DF: uma visão real acerca da implantação da lei 11.161/2005.2014. 249 f. Dissertação (Mestrado em Linguística Aplicada). Universidade de Brasília, Brasília, 2014.

COOPER, R. L. Language planning and social change. Cambridge: Cambridge University Press, 2000.

FAGUNDES, A.; LACERDA, D. P.; SANTOS, G. R. dos. (Org.). \#FicaEspanhol no RS: políticas linguísticas, formação de professores, desafios e possibilidades. 1ed. Campinas: Pontes, 2019.

GARCEZ, P. M; SCHULZ, L. ReVEL na Escola: do que tratam as políticas linguísticas. Revista ReVEL, v.14, n.26, p. 01-19, 2016.

GUIMARÃES, A. História do ensino de espanhol no Brasil. Scientia Plena, v.7, p.1-9, 2011.

LEMOS, M. A. O espanhol em redes de memória. Antigas rotinas e novos sentidos dessa língua no Brasil. 2008. 128 f. Dissertação (Língua Espanhola). Universidade de São Paulo, São Paulo, 2008.

MOITA LOPES, L. P. Por uma linguística aplicada Indisciplinar. São Paulo: Parábola, 2006.

NOGUEIRA, A. M; BAPTISTA, L. M. T. R. Espanhol no Nordeste: espaços de resistência, criação e transformação. Curitiba: CRV, 2018.

OLIVEIRA, G. M. Políticas linguísticas: uma entrevista com Gilvan Muller de Oliveira. Revista ReVEL, v.14, n.26, p. 382-399, 2016.

PAULINO, L. S. A Associação de Professores de Espanhol do Estado da Paraíba (APEEPB) como agente de Política Linguística e sua relação com a Lei Estadual 11.191/2018. Revista Abehache, n.16, 2019/2, p. 92-118, 2019.

PONTE, A. S. Civilización y globalización: gestos de intervención lingüística. Revista Letra Viva - UFPB, v.10, 2010.

SEDYCIAS, J (Org.). O ensino do espanhol no Brasil: passado, presente e futuro. São Paulo: Parábola, 2005.

SIGNORINI, I; CAVALCANTI, M. C. Linguística Aplicada e transdisciplinaridade: questões e perspectivas. Campinas: Mercado de Letras, 1998.

SILVA, M. V. da. (Des)políticas linguísticas no Brasil: a reforma do ensino médio e a exclusão do ensino de língua espanhola na educação básica. Revista Diálogos, v.6, n.2, p.233-245, mai./ago., 2018. 
SOUSA, S. C. T; PONTE, A. S; BERNINI, E. N. S. A área de política e planejamento linguístico no cenário internacional e nacional. In: Fotografias da política linguística na pós-graduação no Brasil. João Pessoa: Editora da UFPB, p. 09-50, 2019.

Recebido em: 29 abr. 2020. Aceito em: 05 out. 2020. 